\title{
Evaluation of structural and ultrastructural changes in thyroid and parathyroid glands after near infrared irradiation - Study on an animal model
}

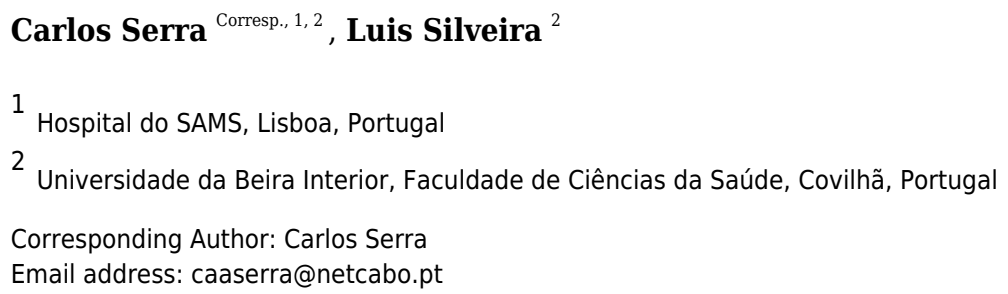

Intraoperative identification of parathyroid glands is a tough task for surgeons performing thyroid or parathyroid surgery, because the small size, color and shape of these glands hinder their discrimination from other cervical tissues. In 2011, Paras described the autofluorescence of parathyroid glands, a property that could facilitate their intraoperative identification. Parathyroid glands submitted to a $785 \mathrm{~nm}$ laser beam emit fluorescence in the near infrared range, with a peak at $822 \mathrm{~nm}$. As the intrinsic properties of secretory tissues may be affected by the exposure to the near infrared light, a situation that could preclude their intraoperative utilization, the authors compared the structural and ultrastructural patterns of rat's thyroid and parathyroid glands submitted to irradiation replicating the conditions that allow their intraoperative identification, with those of non irradiated animals.Twenty-four Wistar rats were divided into six groups: animals of Groups 1,3 and 5 were submitted under general anesthesia to direct irradiation of the cervical area with a $780 \mathrm{~nm}$ LED light for 3 minutes through a cervical incision, and animals of Groups 2, 4 and 6 were submitted to cervical dissection without irradiation. Animals of were euthanized immediately (Groups 1 and 2), at Day 30 (Groups 3 and 4) at and at Day 60 (Groups 5 and 6 ) and thyroid and parathyroid glands were removed: one lobe was prepared for conventional pathological examination and the other lobe for electron microscopy observed by three experienced pathological experts. Twenty-four samples were prepared for conventional histology and there were no alterations reported in any group.Due to technical problems only 20 samples were observed by electron microscopy and there were no differences in the ultrastructure of parathyroid and thyroid glands, namely the nuclear pattern, mitochondria, endoplasmic reticulum or secretory granules, in any of the groups. These results confirm the innocuity of near infrared irradiation ', allowing its intraoperative utilization. 
1 Evaluation of structural and ultrastructural changes in thyroid and parathyroid glands after

2 near-infrared irradiation: Study on an animal model

3

4

5

6

7

8

9

10

11

12

13

14

15

16

17

18

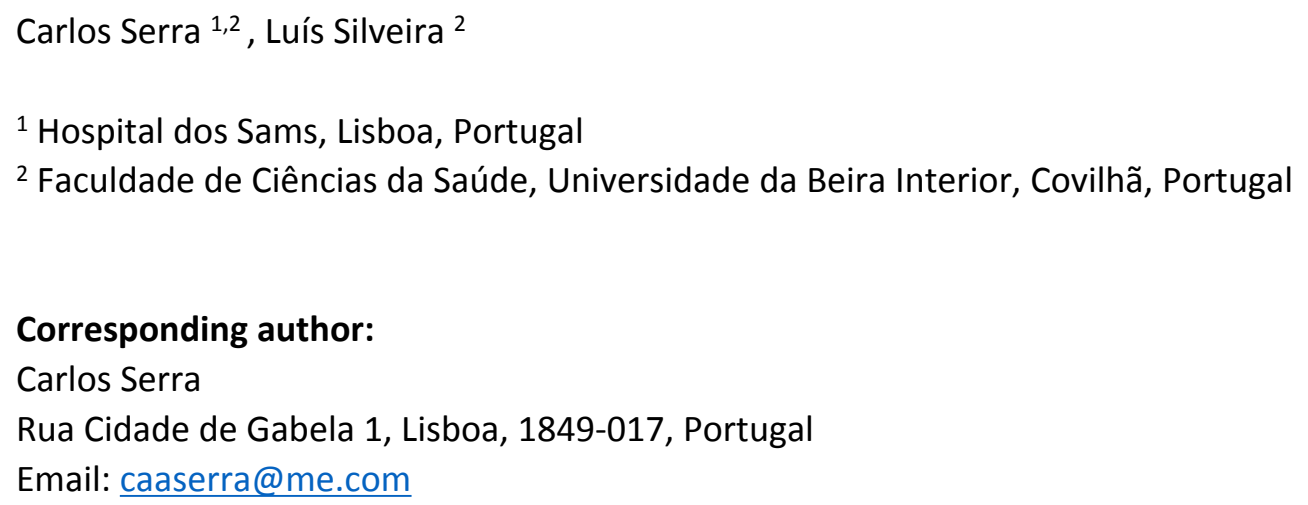

\section{Abstract}

Intraoperative identification of parathyroid glands is a tough ask for surgeons performing thyroid or parathyroid surgery because the small size, colour and shape of these glands hinder their discrimination from other cervical tissues. In 2011, Paras described the autofluorescence of parathyroid glands, a property that could facilitate their intraoperative identification. Parathyroid glands submitted to a $785 \mathrm{~nm}$ laser beam emit fluorescence in the near-infrared range, with a peak at $822 \mathrm{~nm}$. As the intrinsic properties of secretory tissues may be affected by exposure to the near-infrared light, a situation that could preclude their clinical utilization, the authors compared the structural and ultrastructural patterns of rat thyroid and parathyroid glands submitted to irradiation - replicating the conditions that allow their intraoperative identification with those of non-irradiated animals.

Twenty-four Wistar rats were divided into six groups: animals of Groups 1, 3 and 5 were submitted, under general anaesthesia, to direct irradiation of the cervical area with a $780 \mathrm{~nm}$ LED light for 3 minutes through a cervical incision; and animals of Groups 2, 4 and 6 were 
31 submitted to cervical dissection without irradiation. Animals were euthanized immediately

32 (Groups 1 and 2), at Day 30 (Groups 3 and 4) and at Day 60 (Groups 5 and 6) and thyroid and

33 parathyroid glands were removed: one lobe was prepared for conventional pathological

34 examination and the other for electron microscopy, observed by three experienced pathological

35

42 Introduction hypocalcaemia.

experts. Twenty-four samples were prepared for conventional histology and there were no

alterations reported in any group. Due to technical problems, only 20 samples were observed by

electron microscopy and there were no differences in the ultrastructure of parathyroid and thyroid glands, namely the nuclear pattern, mitochondria, endoplasmic reticulum or secretory granules, in any of the groups. These results confirm the innocuity of near-infrared irradiation, allowing its intraoperative utilization.

Hypoparathyroidism is a frequent complication of thyroid surgery, occurring in up to $30 \%$ of total thyroidectomies, and is an important cause of morbidity and litigation.

The parathyroid glands' small size, colour and resemblance to lymph nodes and fat tissue make their intraoperative identification difficult and highly dependent on the surgeon's experience (Akerstrom et al. 1984; Bergenfelz et al. 2020; Edafe \& Balasubramanian 2017). The development of an effective optical device to help surgeons in the identification of parathyroid glands in thyroid and parathyroid surgery could have a strong impact on the reduction of postoperative

51 Paras et al. (2011) described the autofluorescence of parathyroid glands when exposed to a nearinfrared light source, a property that allows their discrimination from other cervical tissues. Parathyroid glands submitted to a $785 \mathrm{~nm}$ laser beam emit fluorescence with a peak at $822 \mathrm{~nm}$. 
54 Even though the thyroid gland also emitted fluorescence at the same wavelength, its inferior

55 intensity allows easy discrimination.

56 Since that first description, other groups have confirmed these results (De Leeuw et al., 2016;

57 Falco, Dip, Quadri, de la Fuente, \& Rosenthal, 2016; S. W. Kim et al., 2016; McWade et al., 2013).

58 Near-infrared radiation is characterized by its capacity to penetrate $5 \mathrm{~mm}$ into biological tissues

59 (Lakowicz, 2006; Monici, 2005; Stolik, Delgado, Perez, \& Anasagasti, 2000). Although the light

60 intensity used for stimulation is small, it is not clear whether it is harmless for tissues, therefore it

61 is important to test the response of the secretory tissues to the irradiation by studying possible

62 structural and ultrastructural changes as well as changes in the secretory pattern.

63 In the literature, works on the effects of utilization of near-infrared radiation for diagnostics and

64 localization of thyroid and parathyroid glands are scarce; however, there are some publications on

65 the effects of this radiation when used with therapeutic intention in dental medicine (Azevedo,

66 Correaaranha, Stolf, Eduardo, \& Ferreira Vieira, 2005; Fronza et al., 2013; Lerma et al., 1991;

67 Mayer, Gomes, Baraldi, Weber, \& Oliveira, 2013; Mohammed, Al-Azawi, \& AL-Mustawfi, 2011;

68 Weber et al., 2014).

69 In spite of the lack of information about possible effects on the structure or function of thyroid and

70 parathyroid glands submitted to near-infrared irradiation, several works have stated its clinical

71 application for intraoperative identification of parathyroid glands with relevant impact in clinical

72 practice (Dip et al., 2019; S. W. Kim et al., 2016; Ladurner et al., 2017; McWade, Sanders,

73 Broome, Solorzano, \& Mahadevan-Jansen, 2016).

74 In a previous work the authors studied the influence of near-infrared radiation emitted by a 780

$75 \mathrm{~nm}$ LED light on the secretory pattern of thyroid and parathyroid glands, replicating the conditions

76 that allow the identification of parathyroid glands by autofluorescence, and concluded that 
77 although some alterations occurred, they are transient and without great significance, thus

confirming the safety of autofluorescence for this purpose (Serra \& Silveira, 2019).

Weber showed that utilization of a low-intensity laser applied to dental alveola of rats after dental extraction and implant collocation could influence thyroid function and calcium levels, whereas Fronza did not find any changes in thyroid hormone levels in rabbits using GaAlAs lasers $(\lambda=$ $830 \mathrm{~nm}, 120 \mathrm{~J} / \mathrm{cm}^{2}$ ) (Fronza et al., 2013; Weber et al., 2014).

Lerma studied structural and ultrastructural changes in thyroid glands of rats submitted to HeNe lasers $\left(\lambda=632 \mathrm{~nm}, 75 \mathrm{~J} / \mathrm{cm}^{2}\right)$ and found mild degenerative changes on conventional histology that recover in less than 3 months. Some minor long-term lesions were also identified using electron microscopy: an increased number of peroxisomes and crystalline structures (Lerma et al., 1991).

In all these studies, exposure of the thyroid and parathyroid area was not direct because irradiation was done via the skin and adjacent soft tissue and only one study analysed possible structural or ultrastructural modifications in the tissues submitted to near-infrared radiation. Furthermore, the different characteristics of the radiation used preclude comparisons.

The structural unit of the thyroid gland in rats, as in humans, is the follicle, which is filled with a secretory product called colloid. Follicles are irregularly spheroid and separated by a delicate fibrovascular stroma containing abundant capillaries, lymphatics and nerves (Asa \& Mete, 2018). Human parathyroid glands (usually four) are tiny yellow-brown glands of size $6 \times 3 \mathrm{~mm}$ localized posteriorly to the thyroid gland (Akerstrom, Malmaeus, \& Bergstrom, 1984; Policeni, Smoker, \& Reede, 2012). By contrast, rats only have one pair of parathyroid glands (originating from the third pharyngeal pouch, as with the human inferior parathyroid glands) that migrate 
99

100

101

102

103

104

105

106

107

108

109

110

111

112

113

114

115

116

117

118

119

120

121

caudally, accompanying the caudal migration of the thymus (Isono, Shoumura, \& Emura, 1990;

Kittel, Ernst, \& Kamino, 1996).

Parathyroid glands are surrounded by a thin fibrous capsule that covers a net of fat tissue, vessels and glandular parenchyma. A rich network of arterioles, venules and capillary vessels vascularize the glands (Chen, 2013; Isono et al., 1990; Kittel et al., 1996).

Normal human parathyroid glands present two types of cells:

- chief cells - small dark cells that produce and release parathyroid hormone (PTH) and turn clear when they release PTH;

- oxyphilic cells - with clear tonality and unknown function, whose number increases with age (Asa \& Mete, 2018).

Rat parathyroid glands are composed only of chief cells. Different tones of chief cells (dark or lighter), which are associated with different functional status, can be seen in adult rats (Isono et al., 1990; Kittel et al., 1996). Chief cells in rats are polygon shaped and organized in cordons or laminate surrounded by a thin stroma of connective tissue and a capillary net (Isono et al., 1990; Kittel et al., 1996). Using conventional staining, the cytoplasm appears granular and is surrounded by an almost imperceptible cellular membrane. Nuclei are round or oval with a fine dispersion of chromatin (Kittel et al., 1996).

On transmission electron microscopy, the plasmatic membrane of chief cells in rats is smooth on the basal side; on the lateral sides, the cells are connected by desmosomes or tight junctions, whereas smooth areas or interdigitations between cells can be found in the internal portion of the cordons. Nuclei have a basal localization and are often indented, with medial electronic density (Kittel et al., 1996). The Golgi apparatus is well developed and located on the apical portion of the cell, as are the secretory granules (Isono et al., 1990; Kittel et al., 1996). 
122 Two types of secretory granules can be found (Chen, 2013; Isono et al., 1990; Kittel et al., 1996):

123 - small granules with a large halo $(100-400 \mathrm{~nm})$;

124 - large granules with a smaller halo (500-700 nm).

125 Mitochondria, rough endoplasmic reticulum and free ribosomes can be found in the chief cells.

126 Rat mitochondria are long and wavy structures (Kittel et al., 1996).

127 In this work we evaluate the structural and ultrastructural patterns of thyroid and parathyroid

128 glands submitted to a $780 \mathrm{~nm}$ LED light - replicating the conditions that allow their

129 identification by autofluorescence in an animal model - compared with those of non-irradiated

130 animals.

131

132

133

134

135

136

137

138

139

140

141

142 143

144

145

\section{Materials \& Methods}

Twenty-four male Wistar rats aged 10-12 weeks, produced in the vivarium of the School of Health Sciences of the University of Beira Interior (UBI), were used in the study. The experimental protocol was approved by the General Directorate of Agriculture and Veterinary Science (Approval number 0421/000/000/2018).

Experiments were conducted according to the methodology described by the same authors is a previous work namely animal housing, anesthesia, surgical procedure and irradiation conditions (Serra \& Silveira, 2019).

The rats were kept in individual ventilated cages (Sealsafe Plus GR 900; Tecniplast S.p.A., Bugiggiatte, Italy) in an animal room under controlled conditions (temperature: $22-24^{\circ} \mathrm{C}$; relative humidity: 40-60\%) and provided with food (Standard Diet 4RF18; Mucedola srl, Settimo Millanese, Italy) and water ad libitum.

Rats were divided into six groups (three experimental; three control) of four animals each and submitted to general anaesthesia via isoflurane inhalation. General anaesthesia was induced with 
$1465 \%$ isoflurane (IsoFlo; Zoetis Inc., Parsippany, NJ, USA) in oxygen (2.4 1/min) and maintained

147 with $2 \%$ isoflurane in oxygen $(2.4 \mathrm{l} / \mathrm{min})$ delivered by a Matrx VME $2 \mathrm{~N}$ anaesthesia machine

148 (Matrx Inc., Orchard Road, New York, USA). After a horizontal cervical incision, neck tissues

149 were dissected to expose the trachea and identify the thyroid gland.

150 For animals in Groups 1, 3 and 5, a $780 \mathrm{~nm}$ light beam emitted by a collimated LED (M780 L3C1;

151 Thorlabs, Newton, NJ, USA) with a $780 \mathrm{~nm}$ excitation bandpass filter (No. 84121, Edmund Optics,

152 Barrington, NJ, USA) was delivered to the cervical area for 180 seconds (dose: $1.37 \mathrm{~J} / \mathrm{cm}^{2}$ ). The

153 fluorescence emitted by the parathyroid and thyroid glands was visualized with a Nikon D70

154 DSLR camera (Nikon Corporation, Tokyo, Japan) converted to infrared radiation capture and a

155 Nikon Nikkor $50 \mathrm{~mm}$ f/1.8 AF M/A lens (Nikon Corporation, Tokyo, Japan) with an $832 \mathrm{~nm}$

156 emission bandpass filter (No. 84123, Edmund Optics, Barrington, NJ, USA). To ensure equal

157 exposure distance for all animals, the LED was coupled to a retention device (Figure 1), with the

158 focus placed approximately $20 \mathrm{~cm}$ from the cervical region (irradiated area: $20 \mathrm{~mm}$; power density:

$1590.067 \mathrm{~W} / \mathrm{cm}^{2}$ ). The exposure time was calculated based on the times reported in the literature for

160 identification of parathyroid glands using similar systems (Sung Won Kim et al., 2018). For 161 animals in Groups 2, 4 and 6, the procedure was done without neck infrared irradiation.

162 Rats in Groups 1 and 2 were euthanized immediately after surgery and a thyroparathyroidectomy 163 was performed. Euthanasia was performed by cardiac puncture under general anaesthesia. 164 Thyroparathyroid blocks were divided by the isthmus, with one half fixed in $10 \%$ formalin for 165 conventional histological examination and the other half fixed in gluteraldehyde for transmission 166 electron microscopy, both conserved at a temperature of $5^{\circ} \mathrm{C}$. Animals in Groups 3, 4, 5 and 6 167 were maintained in similar conditions after surgery, medicated with an analgesic agent (meloxicam $1681 \mathrm{mg} / \mathrm{kg} \mathrm{sc}$, Maxicam 0.2\%; Ourofino Saúde Animal, Osasco, Brazil) and submitted to the same 
169 procedure at Day 30 (Groups 3 and 4) and Day 60 (Groups 5 and 6) postoperatively. Collected 170 tissues were prepared for conventional histological examination at the Centro de Diagnóstico 171 Anatomopatológico (Lisbon, Portugal), stained with haematoxylin-eosin and lamel mounted.

172 Preparation for electron microscopy was done at the Pathology Department of the Hospital 173 Professor Doutor Fernando Fonseca (Amadora, Portugal) using the following procedure: after 174 collection, samples were fixed in gluteraldehyde and buffered in $0.1 \mathrm{M}$ sodium cacodylate with 175 sucrose (primary fixer), $1 \%$ osmium tetroxide in $0.1 \mathrm{M}$ sodium cacodylate with sucrose (secondary 176 fixer) and $0.5 \%$ uranyl acetate in $0.1 \mathrm{M}$ acetate acetic acid. Samples were then dehydrated with 177 crescent concentrations of ethyl alcohol, transitioned with propylene oxide and then embedded in epoxy resin (araldite). Ultrathin cuts were made with a Leica EM UC7 RT ultramicrometer in copper grills (200 mesh, $79 \mathrm{~nm}$ ) and contrasted using Reynolds lead citrate.

Three experienced pathologists examined the samples using optical microscopy, searching for morphological changes in the thyroid or parathyroid glands without knowing about the exposure to near-infrared radiation. A brief report was given of each observation. Observations with transmission electron microscopy were made with a Hitachi H-7650 $120 \mathrm{kV}$ transmission electron microscope in the Laboratório de Microscopia Electrónica, Instituto Gulbenkian de Ciência. Selected images were observed by the same pathologists who carried out the histological examination.

\section{Results}

Table 1 shows the results of optical microscopy of samples collected immediately, 30 days and 60 190 days after exposure, respectively. Pathological examination of the samples did not find significant alterations to the usual follicular structure of thyroid cells in any of the groups. Structural changes 
192 also were not identified in the parathyroid glands, with the chief cells in all the groups having the 193 same characteristics.

194 Technical problems occurred during processing of the tissues so that only 21 samples were 195 amenable to observation using electron microscopy. Table 2 shows the electron microscopy results 196 for samples collected immediately, 30 days and 60 days after exposure. No qualitative 197 ultrastructural alterations were observed using electron microscopy in either the exposed or control 198 groups, suggesting that there was no degeneration of any organelles: mitochondria, rough 199 endoplasmic reticulum, secretory granules and nucleus of both groups had the same characteristics. 200 The presence of peroxisomes or crystalline structures was not observed in any sample. As with

201

202

203

204

205

206

207

208

209

210

211

212 213 conventional histology, no ultrastructural features allowed the distinction between irradiated and non-irradiated tissues using electron microscopy. Figures 2 and 3 show the optical microscopy and electron microscopy images acquired for samples of Groups 1 and 2.

\section{Discussion}

The possibility that irradiation of the thyroid and parathyroid area could promote structural or ultrastructural changes in targeted tissues must be considered when facing the known tissue penetration capacity of near-infrared radiation allied to intrinsic features of endocrine tissues (Stolik et al., 2000). As the magnitude of these changes could preclude the clinical application of near-infrared autofluorescence for intraoperative identification of parathyroid glands, this work reinforces the safety of exposure in a controlled setting, as suggested in a previous study by the same authors directed to changes in secretory pattern and weight variation, thus allowing its utilization (Serra \& Silveira, 2019). 
214 As the doses used were above the maximum necessary for intraoperative identification of 215 parathyroid glands in the rat model, these results can be extrapolated for utilization of this 216 technique in human surgery, in spite of the absence of oxyphilic cells in rats. In our sample no 217 degenerative changes were found in the thyroid gland's conventional histology and no significant difference was documented regarding the presence of peroxisomes or crystalline structures on

219 electron microscopy. Special attention was paid to the features in parathyroid mitochondria and 220 secretory granules but no differences were found between irradiated and non-irradiated tissues.

221 Furthermore, no alterations were found in the nuclei or rough endoplasmic reticulum.

222 Our results are aligned with the work of Lerma, where no significant structural or ultrastructural

223

224

225

226

227

228

230

231

232

233

234

235

236 changes could be found in the thyroid glands of rats submitted to a $635 \mathrm{~nm}$ laser beam (Lerma et al., 1991). More important and persistent alterations could be associated with excessive exposure to light for consecutive days, as shown by Parrado (Parrado, Carrillo de Albornoz, Vidal, \& Pérez de Vargas, 1999), who found a direct relationship between the severity of the injury and the energy of the applied irradiation. This excessive exposure may also explain the significant alteration in hormonal level but no change in the histological structure of the tissues found by Azevedo between the first and seventh day after the last irradiation (Azevedo et al., 2005). The deeper penetration of the laser compared with the LED for the same wavelength could also help to explain the alterations found.

In spite of the absence of structural or ultrastructural alterations in the parathyroid and thyroid glands provoked by exposure to near-infrared irradiation, this study did not evaluate possible changes in the secretory pattern of the glands, which is a major limitation. However, in a previous work the authors showed, in another set of animals, that mild and transient alterations can occur without any clinical impact (Serra \& Silveira, 2019). 


\section{Conclusions}

239

240

241

242

243

244

245

246

247

248

249

250

251

252

253

254

255

256

257

258

259

260

261

262

263

264

265

266

267

268

269

270

The absence of morphological changes in thyroid and parathyroid glands coupled with the mild and transient alterations in secretory pattern of the glands submitted to near-infrared irradiation reinforces the hypothesis that the utilization of near-infrared light for intraoperative identification of parathyroid glands is harmless for the tissues and can be used safely in clinical practice. However, further investigation should be performed to give robustness to this study.

\section{Acknowledgements}

The authors want to thank Drs. Paula Guerra Marques, Sara Turpin and Delfina Brito from the Pathology Department of Hospital dos Sams, for their invaluable help on both optical and electron microscopy observations.

We are also grateful to Professor Erin Tranfield from Instituto Gulbenkian de Ciência that made preliminary electron microscopy of the samples and select the images and to Dra. Rita Manso from Hospital Fernando Fonseca that prepared the samples for observation.

For the performance of animal surgeries, we had the invaluable collaboration of technicians Maria José and Maria João from Universidade da Beira Interior and Dra. Maria do Rosário Custódio, Master on animal behavior

\section{References}

Akerstrom, G., Malmaeus, J., \& Bergstrom, R. (1984). Surgical anatomy of human parathyroid glands. Surgery, 95(1), 14-21.

Asa, S. L., \& Mete, O. (2018). Endocrine pathology: past, present and future. Pathology, 50(1), 111-118. doi:10.1016/j.pathol.2017.09.003

Azevedo, L. H., Correaaranha, A. C., Stolf, S. F., Eduardo, C. D. P., \& Ferreira Vieira, M. M. (2005). Evaluation of low intensity laser effects on the thyroid gland of male mice. Photomedicine and laser surgery, 23(6), 567-570.

Chen, H. S., T. Emura ,S. Kubo, K. (2013). An Update on the structure of the parathyroid gland. The Open Anatomy Journal, 5, 1-9. doi:https://doi.org/10.2174/1877609401305010001

De Leeuw, F., Breuskin, I., Abbaci, M., Casiraghi, O., Mirghani, H., Ben Lakhdar, A., . . Hartl, D. (2016). Intraoperative Near-infrared Imaging for Parathyroid Gland Identification by Auto-fluorescence: A Feasibility Study. World J Surg, 40(9), 2131-2138. doi:10.1007/s00268-016-3571-5 
271

272

273

274

275

276

277

278

279

280

281

282

283

284

285

286

287

288

289

290

291

292

293

294

295

296

297

298

299

300

301

302

303

304

305

306

307

308

309

310

311

312

313

314

315

316

317

318

Dip, F., Falco, J., Verna, S., Prunello, M., Loccisano, M., Quadri, P., . . Rosenthal, R. (2019). Randomized Controlled Trial Comparing White Light with Near-Infrared Autofluorescence for Parathyroid Gland Identification During Total Thyroidectomy. J Am Coll Surg, 228(5), 744-751. doi:10.1016/j.jamcollsurg.2018.12.044

Falco, J., Dip, F., Quadri, P., de la Fuente, M., \& Rosenthal, R. (2016). Cutting Edge in Thyroid Surgery: Autofluorescence of Parathyroid Glands. J Am Coll Surg, 223(2), 374-380. doi:10.1016/j.jamcollsurg.2016.04.049

Fronza, B., Somacal, T., Mayer, L., de Moraes, J. F., de Oliveira, M. G., \& Weber, J. B. (2013). Assessment of the systemic effects of low-level laser therapy (LLLT) on thyroid hormone function in a rabbit model. Int J Oral Maxillofac Surg, 42(1), 26-30. doi:10.1016/j.ijom.2012.06.017

Isono, H., Shoumura, S., \& Emura, S. (1990). Ultrastructure of the parathyroid gland. Histol Histopathol, 5(1), 95-112.

Kim, S. W., Lee, H. S., Ahn, Y.-C., Park, C. W., Jeon, S. W., Kim, C. H., . . Lee, K. D. (2018). Near-Infrared Autofluorescence Image-Guided Parathyroid Gland Mapping in Thyroidectomy. Journal of the American College of Surgeons, 226(2), 165-172.

Kim, S. W., Song, S. H., Lee, H. S., Noh, W. J., Oak, C., Ahn, Y. C., \& Lee, K. D. (2016). Intraoperative RealTime Localization of Normal Parathyroid Glands With Autofluorescence Imaging. J Clin Endocrinol Metab, 101(12), 4646-4652. doi:10.1210/jc.2016-2558

Kittel, B., Ernst, H., \& Kamino, K. (1996). Anatomy, Histology, Ultrastructure, Parathyroid, Rat. In Endocrine System (pp. 330-333): Springer Berlin Heidelberg.

Ladurner, R., Sommerey, S., Al Arabi, N., Hallfeldt, K. K., Stepp, H., \& Gallwas, J. K. (2017). Intraoperative near-infrared autofluorescence imaging of parathyroid glands. Surgical endoscopy, 31(8), 31403145.

Lakowicz, J. R. (2006). Principles of Fluorescence Spectroscopy(pp. 954).

Lerma, E., Hevia, A., Rodrigo, P., Gonzalez-Campora, R., Armas, J. R., \& Galera, H. (1991). The effect of HeNe laser radiation on the thyroid gland of the rat. Int J Exp Pathol, 72(4), 379-385. Retrieved from http://www.ncbi.nlm.nih.gov/pubmed/1883738

Mayer, L., Gomes, F. V., Baraldi, C. E., Weber, J. o. B. B., \& Oliveira, M. I. G. d. (2013). Assessment of LLLT systemic effects on thyroid hormones function after dental titanium implant installation: An experimental rabbit model. Natural Science, Vol.05No.08, 8. doi:10.4236/ns.2013.58113

McWade, M. A., Paras, C., White, L. M., Phay, J. E., Mahadevan-Jansen, A., \& Broome, J. T. (2013). A novel optical approach to intraoperative detection of parathyroid glands. Surgery, 154(6), 13711377. doi:10.1016/j.surg.2013.06.046

McWade, M. A., Sanders, M. E., Broome, J. T., Solorzano, C. C., \& Mahadevan-Jansen, A. (2016). Establishing the clinical utility of autofluorescence spectroscopy for parathyroid detection. Surgery, 159(1), 193-202. doi:10.1016/j.surg.2015.06.047

Mohammed, I., Al-Azawi, T., \& AL-Mustawfi, N. (2011). Effect of laser treatment on thyroid gland hormones in female rabbits. Iraqi Journal of Veterinary Sciences, 25(2), 61-64.

Monici, M. (2005). Cell and tissue autofluorescence research and diagnostic applications. Biotechnol Annu Rev, 11, 227-256. doi:10.1016/S1387-2656(05)11007-2

Parrado, C., Carrillo de Albornoz, F., Vidal, L., \& Pérez de Vargas, I. (1999). A quantitative investigation of microvascular changes in the thyroid gland after infrared (IR) laser radiation. Histol Histopathol, 14(4), 1067-1071. doi:10.14670/hh-14.1067

Policeni, B. A., Smoker, W. R., \& Reede, D. L. (2012). Anatomy and embryology of the thyroid and parathyroid glands. Semin Ultrasound CT MR, 33(2), 104-114. doi:10.1053/j.sult.2011.12.005

Serra, C., \& Silveira, L. (2019). Near-infrared irradiation of the thyroid area: effects on weight development and thyroid and parathyroid secretory patterns. Lasers Med Sci. doi:10.1007/s10103-019-02800-w

PeerJ reviewing PDF | (2021:04:59864:1:1:NEW 18 Jun 2021) 
319 320

321

322

323

324

325

326

327

328

329

Stolik, S., Delgado, J., Perez, A., \& Anasagasti, L. (2000). Measurement of the penetration depths of red and near infrared light in human "ex vivo" tissues. Journal of Photochemistry and Photobiology B: Biology, 57(2-3), 90-93. Retrieved from https://www.sciencedirect.com/science/article/pii/S1011134400000828?via\%3Dihub

Weber, J. B., Mayer, L., Cenci, R. A., Baraldi, C. E., Ponzoni, D., \& Gerhardt de Oliveira, M. (2014). Effect of three different protocols of low-level laser therapy on thyroid hormone production after dental implant placement in an experimental rabbit model. Photomed Laser Surg, 32(11), 612617. doi:10.1089/pho.2014.3756 


\section{Table $\mathbf{1}$ (on next page)}

Results of optical microscopy of samples collected immediately after exposure, 30 and 60 days after exposure 
1

2

3

4 Table 1 - Results of optical microscopy of samples collected immediately after exposure, 30 and 60 days

5 after exposure

6

7

\begin{tabular}{lllll}
\hline $\mathrm{n}$ & Thyroid identified & $\begin{array}{c}\text { Morphological } \\
\text { alterations on thyroid }\end{array}$ & $\begin{array}{l}\text { Parathyroid } \\
\text { identified }\end{array}$ & $\begin{array}{l}\text { Morphological alterations } \\
\text { on parathyroid }\end{array}$ \\
\hline
\end{tabular}

\section{After exposure}

\begin{tabular}{llllll}
\hline Exposed (group 1) & 4 & 4 & 0 & 4 & 0 \\
\hline Control (group 2) & 4 & 4 & 0 & 3 & 0
\end{tabular}

830 days after exposure

\begin{tabular}{llllll}
\hline Exposed (group 3) & 4 & 4 & 0 & 4 & 0 \\
\hline Control (group 4) & 4 & 4 & 0 & 3 & 0
\end{tabular}

960 days after exposure

\begin{tabular}{llllll}
\hline Exposed (group 5) & 4 & 4 & 0 & 4 & 0 \\
\hline Control (group 6) & 4 & 4 & 0 & 3 & 0
\end{tabular}

10

11

12

13

14 
Table 2 (on next page)

Results of electron microscopy of samples collected immediately after exposure, 30 and 60 days after exposure 
1

2

3 Table 2 - Results of electron microscopy of samples collected immediately after exposure, 30 and 60

4 days after exposure

5

6

7

Ultrastructural alterations

$\mathbf{N}$

Thyroid

Parathyroid

\section{After Exposure}

\begin{tabular}{llcc}
\hline Exposed (group 1) & 4 & 0 & 0 \\
\hline Control (group 2) & 3 & 0 & 0
\end{tabular}

$8 \mathbf{3 0}$ days after exposure

Exposed (group 3) 4

\begin{tabular}{llll}
\hline Control (group 4) & 3 & 0 & 0
\end{tabular}

$9 \mathbf{6 0}$ days after exposure

\begin{tabular}{llll}
\hline Exposed (group 5) & 4 & 0 & 0 \\
\hline Control (group 6) & 3 & 0 & 0
\end{tabular}

10

11

12

13

14 
Figure 1

Intraoperative image showing the LED source 


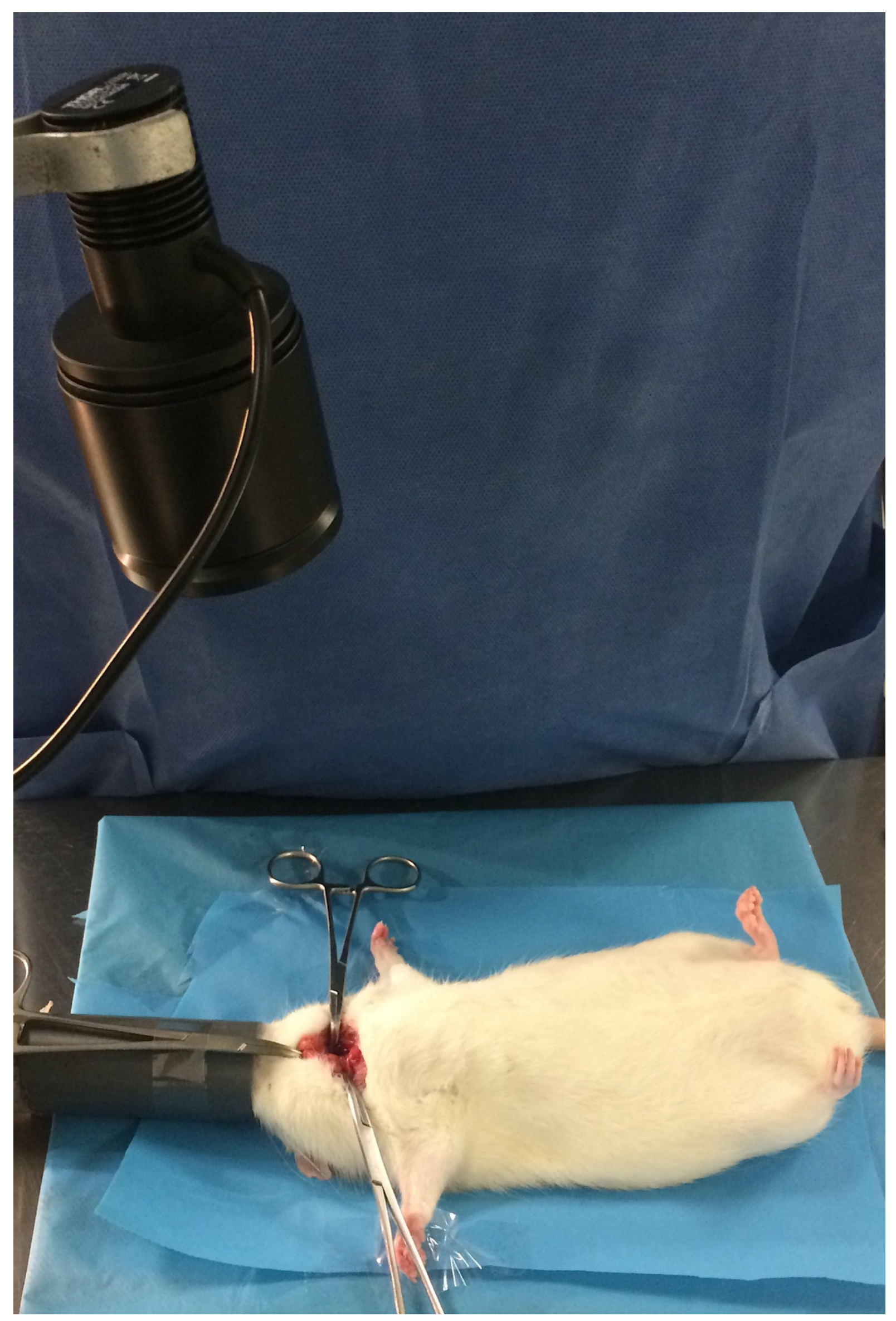

PeerJ reviewing PDF | (2021:04:59864:1:1:NEW 18 Jun 2021) 
Figure 2

Optical microscopy of parathyroid samples of groups 1 (left) and 2 (right) HE X100

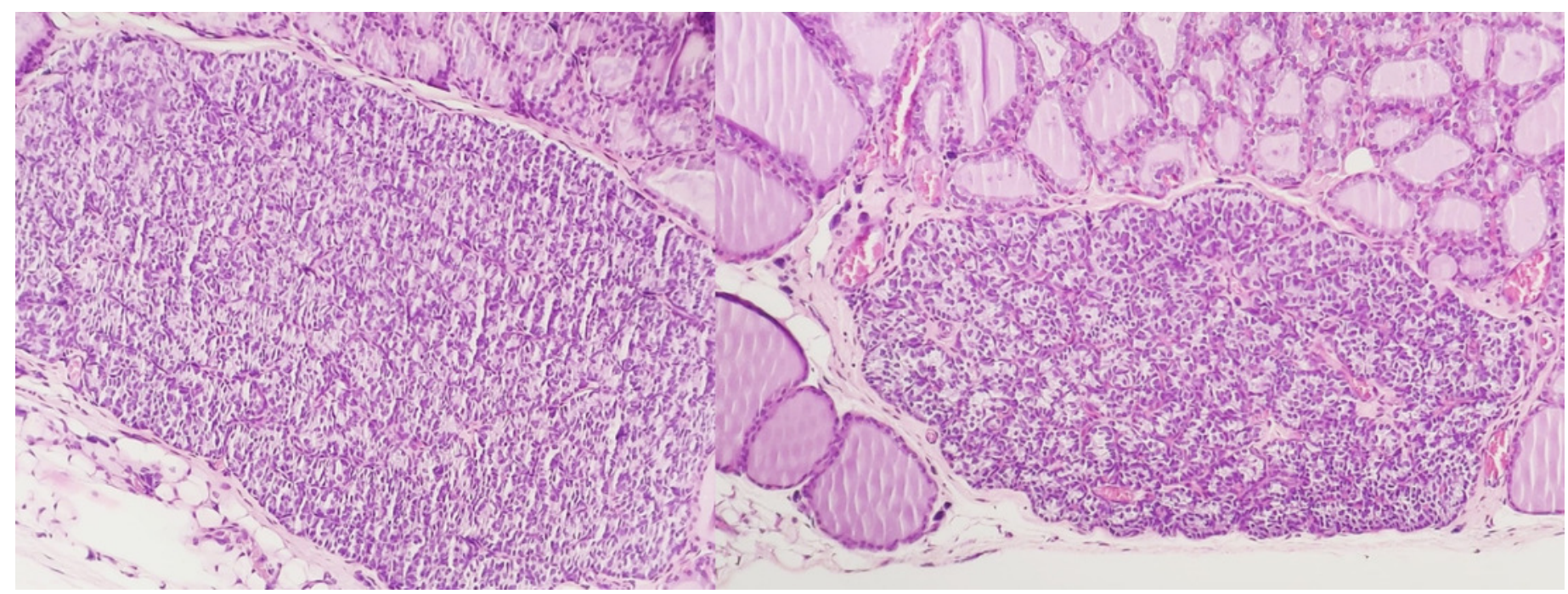


Figure 3

Electron microscopy of parathyroid samples of groups 1 (left) and 2 (right). X 25600

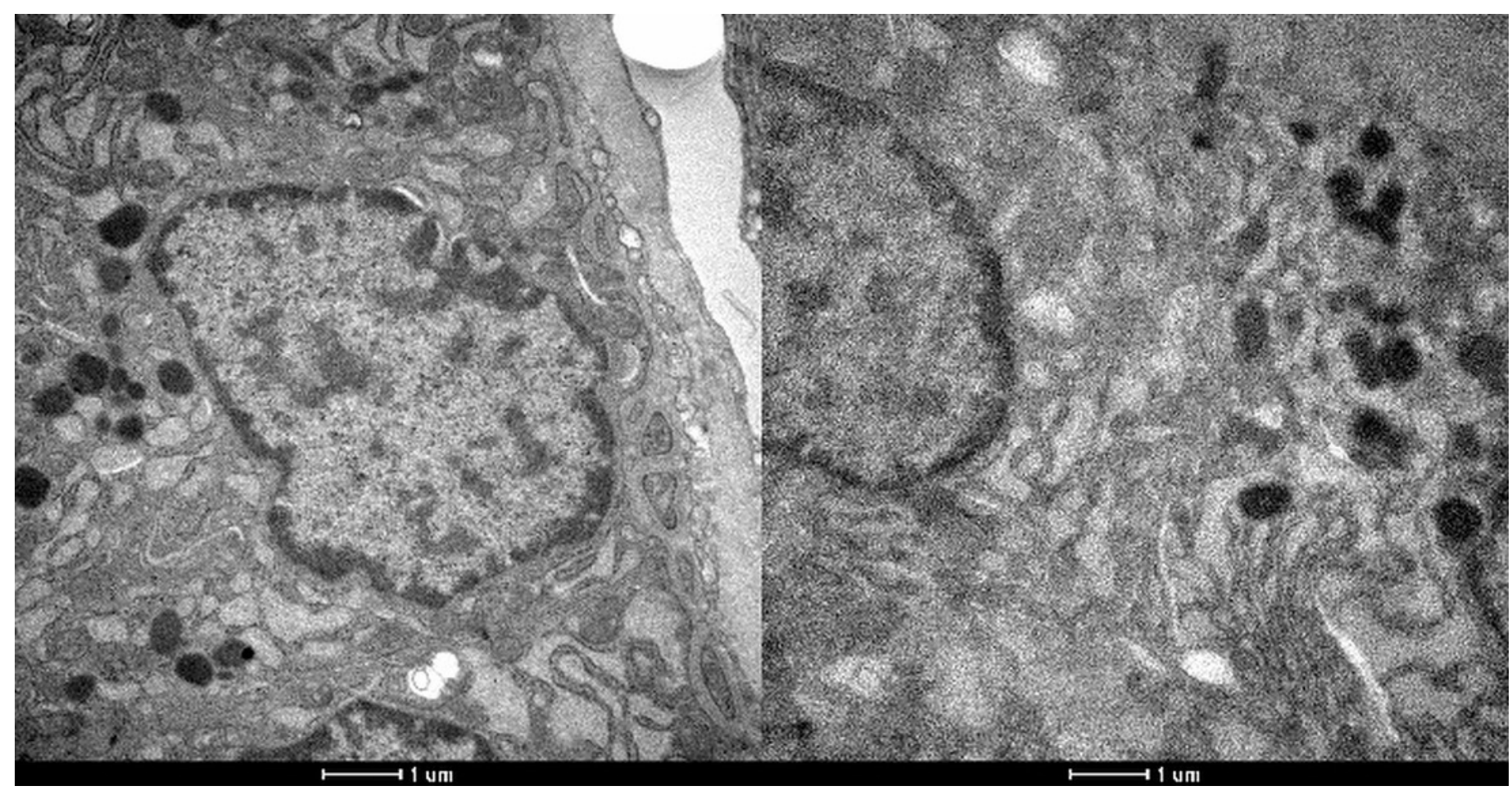

